\title{
Synergistic effects of predators and trematode parasites on larval green frog (Rana clamitans) survival
}

\author{
John A. Marino, JR., ${ }^{1}$ And EARl E. Werner \\ Department of Ecology and Evolutionary Biology, University of Michigan, 830 N. University Ave., \\ Ann Arbor, Michigan 48109-1048 USA
}

\begin{abstract}
Parasites and predators can have complex, nonadditive effects on a shared group of victims, which can have important consequences for population dynamics. In particular, parasites can alter host traits that influence predation risk, and predators can have nonconsumptive effects on prey traits which influence susceptibility (i.e., infection intensity and tolerance) to parasites. Here, we examined the combined effects of trematode parasites (Digenea: Echinostomatidae) and odonate (Anax) predators on the survival of larval green frogs (Rana clamitans). First, in a large-scale mesocosm experiment, we manipulated the presence or absence of parasites in combination with the presence of no predator, caged predators, or free predators, and measured survival, traits, and infection. Parasites, caged predators, and free predators decreased survival, and we found a strong negative synergistic effect of parasites in combination with free predators on survival. Importantly, we then examined the potential mechanisms that explain the observed synergistic effect of parasites and predators in a series of follow-up experiments. Results of the follow-up experiments suggest that increased predation susceptibility due to elevated activity levels in the presence of free-swimming parasite infective stages (i.e., an avoidance response) is the most likely mechanism responsible for the observed synergism. These results suggest a potential trade-off in susceptibility to parasites and predators, which can drive nonadditive effects that may have important consequences for natural enemy interactions in natural populations and amphibian conservation.
\end{abstract}

Key words: Anax spp.; Echinostomatidae; green frog; larval survival; mesocosms experiment; odonate predators; parasite-host interactions; Planorbella trivolvis; predator-prey interactions; Rana clamitans; synergistic effects; trematode parasites.

\section{INTRODUCTION}

Species are inevitably embedded in complex food webs, in which they interact with multiple natural enemies, competitors, and resources. Classically, interactions between these species have been studied pairwise in isolation, despite the acknowledged importance of higher order interactions (Wootton 1994, Peacor and Werner 2004). In particular, trait-mediated effects are a widespread source of higher order effects and can be comparable in magnitude to density-mediated effects (Bolker et al. 2003, Werner and Peacor 2003). Interactions between parasites and predators are a common source of trait-mediated effects (reviewed in Hatcher et al. 2006), which can have nonadditive, often synergistic, effects on a shared group of victims (e.g., Johnson et al. 2006, Ramirez and Snyder 2009, Duffy et al. 2011). These nonadditive effects are understudied, despite evidence that there may be important implications for

Manuscript received 28 February 2013; revised 12 June 2013; accepted 19 June 2013. Corresponding Editor: D. M. Tompkins.

${ }^{1}$ Present address: Department of Ecology and Evolutionary Biology, University of Michigan, 2010B Kraus Natural Science Building, 830 N. University Ave., Ann Arbor, Michigan 48109-1048 USA. E-mail: jamarino@umich.edu population dynamics (e.g., Hudson et al. 1992, Ives and Murray 1997, Dwyer et al. 2004, Fenton and Rands 2006) and community structure (e.g., Thomas et al. 1998, Lefevre et al. 2009). Understanding both the relative strength of such effects and the underlying mechanisms will be crucial to developing a predictive theory of natural enemy ecology.

Predators and parasites in combination may have interactive effects on shared victims through several mechanisms. For instance, parasites may affect host traits, such as behavior (Poulin 1994, Rohr et al. 2009) and growth (Palacios et al. 2012), which can influence susceptibility to predators (e.g., Kagan 1951, Lafferty and Morris 1996, Behringer and Butler 2010). Such host trait modifications may reduce costs of parasitism for hosts (e.g., anti-parasite behavior; Hart 1990) or increase parasite fitness (e.g., parasite-increased trophic transmission; Lafferty 1999, Lagrue et al. 2007), although many trait effects of parasites are not necessarily adaptive (Poulin 1995). These effects on traits may affect predation rates by increasing predatorprey encounter rates or reducing prey escape ability. In addition, nonlinearities in predator-prey (e.g., Type II functional response; Holling 1959) or parasite-host interactions (e.g., Diaz and Alonso 2003, Luong et al. 2011) may lead to nonadditive effects. For example, 
predators can reduce host densities, which may increase the ratio of parasite infective stages to hosts, thereby resulting in higher per capita infection rates. These density-mediated effects of predators on infection rates may lead to an interactive effect on mortality, if mortality increases nonlinearly with infection intensity. Finally, the presence of predators may influence traits of prey, such as behavior (Relyea 2001a), growth (Relyea 2004), or immunocompetence (Horak et al. 2006), that in turn influence susceptibility to parasites (Ramirez and Snyder 2009, Duffy et al. 2011). Such trait changes may be adaptive prey defenses (Van Buskirk and McCollum 2000 , Relyea 2001b) or nonadaptive by-products of other trait changes (Bourdeau and Johansson 2012). The consequence of these predator-induced trait changes may be higher infection rates or reduced tolerance of infection. All of these mechanisms potentially could drive interactive effects that may have important implications for parasite transmission and population dynamics.

Here, we examined the separate and combined effects of predators and trematode (Digenea: Echinostomatidae) parasites on larval frogs, and then we evaluated potential underlying mechanisms that were responsible for interactions. Larval frogs exhibit an array of trait effects in response to parasites (e.g., Rohr et al. 2009, Raffel et al. 2010) and predators (e.g., Relyea 2001a, 2004), which can drive interactive effects (Thiemann and Wassersug 2000, Belden and Wojdak 2011). First, we hypothesized that parasites (echinostomes) and predator (larval odonate) cues interact synergistically to decrease tadpole survival, because of a documented positive effect of visual and chemical predator cues on echinostome infection intensity (Thiemann and Wassersug 2000, Szuroczki and Richardson 2012). Second, we hypothesized that echinostomes further interact with direct predation to decrease survival, because parasites can affect traits involved in predation susceptibility. To test these hypotheses, we conducted a large-scale mesocosm experiment in which we examined the effects of echinostome parasites in combination with caged predators (i.e., nonconsumptive effects) and direct predation (i.e., consumptive and nonconsumptive effects) on traits and survival. As a key next step, we then performed a series of follow-up experiments to evaluate the contribution of potential mechanisms driving synergistic effects.

\section{Methods \\ Study system}

Echinostomes infect the kidneys of larval frogs, causing edema and often death at high infection intensities in early Gosner (1960) stage tadpoles (Holland et al. 2007). In addition, echinostomes can also affect larval amphibian growth (Fried et al. 1997) and behavior (e.g., parasite avoidance; Koprivnikar et al. 2006, Rohr et al. 2009). Echinostomes have a complex life cycle involving three hosts and can exploit multiple host species during each life stage (Kanev et al. 2000). A free-living miracidium hatches from an egg released in the feces of the definitive host (mammal or bird), which infects a snail host. Within the snail host, the parasite undergoes asexual reproduction during sporocyst and multiple redia stages before a freeswimming cercaria stage is released. Cercariae then infect the second-intermediate host (snail, larval amphibian, or fish). In larval amphibians, cercariae enter via the cloaca and encyst in the kidney, forming metacercariae. When the definitive host consumes the second-intermediate host, the parasite develops into an adult in the definitive host's digestive tract and reproduces sexually.

Green frog (Rana clamitans) larvae are common hosts for echinostomes in ponds in the eastern and central United States (Najarian 1954, Skelly et al. 2006). At our study site in southeastern Michigan, green frogs breed from late May to early August, and larvae typically overwinter in ponds before metamorphosis.

\section{General methods and animal care}

Tadpoles used in experiments were from egg masses collected from the Edwin S. George Reserve (ESGR; University of Michigan, Pinckney, Michigan, USA) experimental ponds and moved into 300-L pools containing aged well water. After hatching, tadpoles were fed Purina Rabbit Chow ad libitum until the beginning of experiments. Gosner (1960) stage 25 tadpoles were used at the initiation of experiments in both mesocosms and aquaria. Aquaria experiments occurred in plastic boxes $(26 \times 38 \times 14 \mathrm{~cm})$ filled with $8 \mathrm{~L}$ of water, during which tadpoles were fed $6 \%$ of their biomass per day with 3:1 Purina Rabbit Chow: TetraMin Fish Flake mixture every 2-3 days. Water used in the laboratory was reverse-osmosis and UV-filtered well water with $63 \mathrm{mg} / \mathrm{L}$ of API aquarium salt added.

Predators were a combination of late-stage larval odonates Anax longipes and A. junius (common predators of larval frogs) collected from the ESGR experimental ponds. Parasites were from Planorbella trivolvis snails, a first-intermediate host of echinostomes, collected from three natural ponds on the ESGR and from two nearby ponds, Duck Pond (42.481308 N, -83.983442 W) and Kaiser South Pond (42.430299 N, -84.036582 W), in Livingston County, Michigan, USA. To determine infection status, snails were placed in $60 \mathrm{~mL}$ water $10 \mathrm{~cm}$ underneath a $60-\mathrm{W}$ lamp for at least $4 \mathrm{~h}$ to stimulate cercariae shedding. Cercariae were identified to family (i.e., Echinostomatidae) using a taxonomic key (Schell 1985). This research was performed in accordance with University of Michigan UCUCA Protocol \#07765.

\section{Experiment 1: Combined effects of echinostomes and predators}

We performed a $3 \times 2$ factorial experiment in mesocosms (1300-L cattle watering tanks; $150 \mathrm{~cm}$ 
diameter $\times 75 \mathrm{~cm}$ depth) to examine the effects of predators, echinostomes, and their combination on larval green frogs. The three predator treatments consisted of no predators, two individually caged Anax, and two free Anax. Caged Anax release chemical cues and thus allow us to examine the nonconsumptive effects of predators independent of consumptive effects. Each caged predator was fed a total mass of $300 \mathrm{mg}$ of green frog tadpoles three times per week throughout the duration of the experiment. The cages were constructed from a $10 \times 10 \mathrm{~cm}$ piece of slotted drain pipe with the ends covered with window screen attached by rubber bands. Each cage contained a small piece of polystyrene so that it would float at the surface of the mesocosm. Empty cages were placed in containers in the other treatments. We manipulated the presence of parasites in tanks by stocking either three infected or three uninfected $P$. trivolvis snails $(\sim 1 \mathrm{~g})$. The three snails were placed together into a cage (same type as for predators), along with three pieces of polystyrene, and the cage was placed into the appropriate treatment. Each treatment combination was replicated five times, and we used a randomized-block design.

Between 30 June and 1 July 2010, the cattle tanks were filled with well water and covered with $60 \%$ shade cloth to exclude colonization by other frogs and predators. On 2 July, we inoculated each tank with zooplankton and phytoplankton, and we added $300 \mathrm{~g}$ of leaf litter (mostly Quercus) to provide a natural substrate and $25 \mathrm{mg}$ Purina Rabbit Chow to provide food and nutrients. On 5 and 6 July (day 1 and 2), we added 200 green frog larvae $(12.7 \pm 0.6 \mathrm{mg}$, mean $\pm \mathrm{SE})$, originating from six egg masses (collected on 17 and 18 June) to each tank. Caged snails and predators were then added to appropriate containers on the evening of day 2. We also placed a cage in each mesocosm containing 10 green frog tadpoles on day 5. Infection of caged tadpoles provided a separate measure independent of any selective predation by free predators that may have affected the observed infection in non-caged tadpoles. Cages $(30 \times 45 \times 5 \mathrm{~cm})$ were constructed of window screening covering a frame of plastic fencing. Tadpoles were added to each cage along with three pieces of polystyrene, and the cage was closed with two plastic zip ties. The cages were removed on day 24 , and surviving tadpoles were counted, weighed, euthanized, and preserved in $70 \%$ ethanol for later dissection.

To measure behavior, two observers conducted observations of tadpoles by slowly circling each tank and counting the number of visible individuals that were active (moving) using scan sampling (Altmann 1974). We performed five replicate sets of observations over $2 \mathrm{~h}$ on four dates (days 8, 12, 18, and 23), all occurring between 08:00 and 18:00 hours. To estimate infection midway through the experiment, 10 tadpoles from each tank were removed, euthanized, and preserved in $70 \%$ ethanol on day 14. To estimate survival midway through the experiment, we took a standardized sample of tadpoles from each tank on day 17. First, we used a "pipe sampler" to sample all animals within a $0.1 \mathrm{~m}^{2}$ of water column within each tank. The pipe sampler was constructed of aluminum pipe $76 \mathrm{~cm}$ long and $36 \mathrm{~cm}$ diameter, fitted with handles at the top. The sampler was quickly thrust down in the center of each tank to trap any animals within the column, and all animals within were counted by sweeping through with a dip net $(22 \times$ $27 \mathrm{~cm}$ with a $1 \times 2 \mathrm{~mm}$ mesh size) until we had 10 sweeps that captured no animals. Second, we performed an additional 10 sweeps of the dip net through other regions of the tank and counted the number of individuals captured with each sweep. The total number of tadpoles captured was used to estimate survival, and all animals were returned to the tank at the end of sampling.

The experiment was terminated on days 26 and 27. We haphazardly selected and weighed 25 individuals (or all, if fewer survived), and then all tadpoles were euthanized and preserved in $10 \%$ buffered formalin. To measure infection intensity, five tadpoles collected on day 14 and five from the end of the experiment (except one container where only one individual survived) were dissected under a microscope using fine forceps. We also dissected five tadpoles (or all surviving when fewer) from the mesh cages in each tank. Unfortunately, we could not measure infection intensity of tadpoles that died during this and subsequent mesocosm experiments because they were consumed by predators or decomposed rapidly before the end of experiments. During dissections, we counted the number of metacercariae present in the mesonephri, nephric ducts, and pronephri.

Survival was analyzed using ANOVA to make three orthogonal comparisons: no predator vs. caged predator, no predator vs. free predator, and caged predator vs. free predator. These comparisons allowed us to assess the contribution of nonlethal predator effects to the overall effects of predators separately and in combination with parasites. We analyzed both midexperiment (day 17) estimated survival and final (day 26) survival, because an interaction may be difficult to detect if few individuals in some treatments survived to the end of the experiment. Final mass and Gosner stage were analyzed using MANOVA. Survival, mass, and stage were log-transformed prior to analysis, because a multiplicative model better represents the potential interactive effects of multiple natural enemies (Vonesh and Osenberg 2003). Activity (mean proportion active across dates) was analyzed using ANOVA only for the no predator vs. caged predator comparison, because few or no tadpoles were visible in the free predator treatment containers on most dates to calculate activity. Activity was arcsine square-root-transformed to improve normality. The mean number of encysted metacercariae (day 14 and final) across predator treatments was analyzed using repeated-measures ANOVA. Log-transformed survival, final mass, and infection of caged tadpoles were analyzed using ANOVA. All analyses in 
this study were performed in the $\mathrm{R}$ statistical package v. 2.15 ( $\mathrm{R}$ Development Core Team 2012).

\section{Follow-up experiments to evaluate potential mechanisms}

Following Experiment 1, we performed a series of additional experiments to examine four potential mechanisms (A-D) underlying interactive effects of predators and parasites, as follows. (A) Cercariae may affect traits (e.g., parasite avoidance behavior, Koprivnikar et al. 2006, Rohr et al. 2009) that cause increased visibility and higher predator encounter rates, thereby leading to increased predation susceptibility. (B) Infection may affect traits that impair predator escape ability, thereby leading to increased predation susceptibility. (C) Decreases in density due to consumption by predators may increase per capita infection rates, if infection rates are density dependent. (D) Predator cue may increase infection rates or reduce tolerance through effects on host behavior and physiology.

\section{Experiment 2: Effects of cercariae exposure on predation risk}

To measure the effects of cercariae exposure on predation susceptibility (Mechanism A), we performed a set of predator trials in aquaria in which tadpoles were exposed to Anax in the presence or absence of cercariae. On 26 August 2011, 10 tadpoles (42.6 $\pm 2.3 \mathrm{mg}$, originating from eight egg masses [collected on 15 and 26 July]) were placed into 40 aquaria. After $30 \mathrm{~min}$, we added one infected or uninfected snail to each aquarium. After another $30 \mathrm{~min}$, we added a small amount of predator cue (water from five 1-L containers containing Anax fed $100 \mathrm{mg}$ of tadpoles was divided among aquaria, $\sim 100 \mathrm{~mL}$ cue per aquarium) to alert tadpoles of impending predator presence, and finally we placed one Anax into each aquarium. Anax were sorted visually by size, and comparably sized Anax were used in the uninfected and infected snail treatments. Aquaria also contained a piece of window screen $(\sim 3 \times 30 \mathrm{~cm})$ to provide a perching structure for Anax. We counted the number of surviving tadpoles in each container every 30 min and terminated the experiment after $6 \mathrm{~h}$. We compared time to the first predation event in each aquarium using Cox proportional hazards survival analysis (the coxph function in the $\mathrm{R}$ survival package, available online $)^{2}$

\section{Experiment 3: Effects of echinostome infection on predation risk}

To evaluate the effects of echinostome infection on predation susceptibility (Mechanism B), we performed a series of predator trials in mesocosms. Groups of tadpoles were exposed to three infected or three uninfected snails and empty cages or two caged predators in an initial set of mesocosms (hereafter,

${ }^{2}$ http://cran.r-project.org/web/packages/survival/ exposure tanks), and then subsets of tadpoles were moved to a new set of cattle tanks (hereafter, trial tanks), where predator trials were performed in the absence of cercariae (i.e., post-exposure). Exposure tanks were thus set up using a $2 \times 2$ factorial design similar to the caged vs. no predator treatments in Experiment 1. These treatments allowed us to assess the effects of echinostome infection and prior exposure to predator cue on predation rates during predator trials. The presence or absence of caged predators was manipulated to assess whether parasitism inhibits adaptive trait responses to predators, which anuran larvae can exhibit (Relyea 2001b). Exposure tanks were 32 1300-L cattle tanks set up as in Experiment 1 (tanks filled and leaf litter added 20-21 June 2011, inoculated with plankton and rabbit chow added on 24 June). We added 250 tadpoles $(16.0 \pm 0.6 \mathrm{mg}$, originating from seven egg masses [collected on 8 and 10 June]) to exposure tanks on 27 June, and added caged predators and snails on 29 June.

Two sets of predator trials were conducted in 32 trial tanks at 8 and 15 days after treatments were instituted in exposure tanks. Trial tanks were filled with well water and covered with $60 \%$ shade cloth on 1 July, and $300 \mathrm{mg}$ of leaf litter was added before each trial. One and two weeks after the predator and parasite treatments were instituted in the exposure tanks, we haphazardly moved 40 individuals from each exposure tank into a trial tank, thereby removing them from exposure to cercariae and predator cues. Additional samples were also collected from exposure tanks on each date to estimate mass (10 tadpoles on each date) and infection intensity (5 tadpoles dissected from first week, 10 from second week) of tadpoles used in predation trials. Tadpoles in trial tanks were fed $10 \%$ of their biomass of rabbit chow per day. We added two Anax to each trial tank $24 \mathrm{~h}$ after tadpoles were moved into trial tanks, thereby initiating the predation trials. After another $24 \mathrm{~h}$, all tadpoles were removed from trial tanks and were counted, euthanized, and preserved. Mortality in trial tanks after the 24-h trial was used to estimate predation rate. Each treatment combination was replicated seven times, with one additional set of tanks used to estimate survival of the 40 tadpoles in the absence of predators. Predation rate during trials performed during weeks 1 and 2 and logtransformed tank means for mass and infection of tadpoles on each date were analyzed using repeatedmeasures ANOVA. The remaining tadpoles in exposure tanks were collected on 14 and 15 July, and logtransformed final survival was analyzed using ANOVA.

\section{Experiment 4: Density-dependent infection rates}

To evaluate the effects of density on infection rates (Mechanism C), we performed a mesocosm experiment in which tadpoles were exposed to parasites at a range of densities. Density depends on both the number of animals and spatial scale, so we manipulated both factors here. We performed a $3 \times 8$ factorial mesocosm 
experiment in which we manipulated both the initial number of tadpoles per container $(25,50,75,100,125$, 150, 200, and 250 tadpoles) and spatial scale (i.e., container size: $100 \mathrm{~L}$ [diameter $\times$ depth $=90 \times 20 \mathrm{~cm}$ ], $300 \mathrm{~L}[120 \times 30 \mathrm{~cm}]$, and $1300 \mathrm{~L}[150 \times 75 \mathrm{~cm}])$. We had one missing treatment $(300 \mathrm{~L} \times 75$ tadpoles). We also had six additional containers to assess tadpole survival in the absence of parasites: two containers of each size, stocked with either 50 or 250 animals. All containers were filled with aged well water and $\sim 100 \mathrm{mg}$ of leaf litter. On 29 July 2011, tadpoles (17.5 $\pm 1.3 \mathrm{mg}$, originating from 14 egg masses [collected between 28 June and 1 July 2011]) were moved into containers. Three infected snails were then added in cages to each treatment container. Tadpoles were fed $10 \%$ of their biomass per day with 3:1 Purina Rabbit Chow: TetraMin Fish Flake mixture on day 1 and 4 of the six day experiment.

Because temperature can influence the rate at which snails shed cercariae (Morley et al. 2010), we also assessed temperature differences between different-sized containers. HOBO pendant UA-001-64 temperature loggers (Onset Computer Corporation, Onset, Massachusetts, USA) were placed in one container of each size to measure water temperature over a 24-h period (beginning at 12:00 hours on 3 August). The loggers were suspended with weights from a floating piece of polystyrene $6 \mathrm{~cm}$ from the water surface. On 6 August, the experiment was terminated and all animals were collected, euthanized, and preserved in $70 \%$ ethanol. Ten tadpoles were haphazardly selected from each of the containers and dissected to measure infection loads. Log-transformed survival and tank mean infection intensity were analyzed using linear models. AIC values were calculated for all permutations of both predictors and the interaction to determine which terms to include in the final models.

\section{Experiment 5 and 6: Effects of predator cue on parasite susceptibility}

To evaluate the effect of predator cue on infection rates and survival after parasite exposure (Mechanism D), we performed two experiments in 8-L aquaria using controlled exposures to cercariae and a gradient of predator cue concentrations. For both experiments, cercariae were collected from infected snails placed $\sim 10 \mathrm{~cm}$ beneath a $60-\mathrm{W}$ light. We counted cercariae in a watch glass under a dissecting microscope and moved into plastic cups containing $60 \mathrm{~mL}$ water, and all cercariae were introduced to tadpole hosts within $8 \mathrm{~h}$ of leaving snail hosts.

Experiment 5 examined the effects of predator cue on infection rates. We used a $3 \times 2$ factorial design with 10 replicates in which we exposed green frog larvae to three predator cue concentrations (none, low, or high) and 0 or 200 echinostome cercariae. On the morning of 17 August 2011, five tadpoles $(23.8 \pm 1.1 \mathrm{mg}$, originating from four egg masses [collected on 26 July]) were moved into each aquarium and allowed $1 \mathrm{~h}$ to acclimate. To produce predator cues, two sets of seven Anax were placed in plastic cups containing $0.5 \mathrm{~L}$ of water and were fed either $100 \mathrm{mg}$ or $300 \mathrm{mg}$ of green frog larvae to generate the low- and high-cue treatments, respectively. The water from containers for each treatment was then mixed together in a bucket and divided evenly among the aquaria at each cue level $(\sim 175 \mathrm{~mL}$ cue per aquaria). Predator cue was added to aquaria $2 \mathrm{~h}$ after tadpoles were added; water was used for the no-cue treatment. We added 0 or 200 cercariae in $60 \mathrm{~mL}$ water to aquaria 1 $\mathrm{h}$ after predator cue addition. We performed behavior observations $15 \mathrm{~min}$ after addition of cercariae by slowly approaching aquaria and counting the number of individuals that were active over a 5-s interval. We performed 10 sets of observations ( $\sim 9 \mathrm{~min}$ per set) over 90 min. After $48 \mathrm{~h}$, all tadpoles were collected, euthanized, preserved in $70 \%$ ethanol, and later dissected to measure infection loads. Log-transformed infection intensity (tank mean) and arcsine square-roottransformed activity (mean proportion active) were analyzed using ANOVA.

Experiment 6 examined how predator cue concentration affects the survival of tadpoles after parasite exposure (i.e., removed from any effect of cue on initial infection intensity). We used a $13 \times 3$ factorial design varying predator cue concentrations (none, low, and high) and parasite exposure levels $(0,5,10,20,25,30$, $35,40,45,50,55,60$, or 65 cercariae per individual). Each parasite exposure level was crossed once with each predator cue concentration level, with the exception that we had two sets of the 20 cercariae treatment. On 19 July 2011, tadpoles $(22.7 \pm 1.2 \mathrm{mg}$, originating from $14 \mathrm{egg}$ masses [collected on 28 June and 1 July]) were moved into the laboratory and allowed to acclimate $1 \mathrm{~h}$ prior to beginning parasite exposure. Tadpoles were then added individually to plastic cups containing $60 \mathrm{~mL}$ of water and the appropriate number of cercariae. Tadpoles were left in the cups overnight (12-18 h) to ensure exposure, and then five tadpoles were moved to the aquaria of appropriate treatments on the following morning. Aquaria contained either an empty cage or a caged Anax. Predators in the low and high treatments were fed $100 \mathrm{mg}$ and $300 \mathrm{mg}$ of tadpoles three times per week during the two-week experiment. We changed the water in aquaria after one week. Behavior observations were performed $72 \mathrm{~h}$ after parasite exposure. The number of active tadpoles was counted for each aquarium 10 times over $90 \mathrm{~min}$, as in Experiment 5. We measured survival over the two weeks and final mass at the end of the experiment. Final survival was analyzed using ordinal logistic regression, and log-transformed final mass and arcsine square-root-transformed activity were analyzed using linear models. We did not measure infection intensity in this experiment, but parasite exposure level is strongly correlated with infection load using the method employed here (J. A. Marino, unpublished data). 


\section{Parasite identification to species}

One infected snail from each pond was used for species-level parasite identification. Infected snails used for identification were preserved in $70 \%$ alcohol for later dissection. Five parasite larval stages (sporocysts or rediae) were dissected from snails and DNA was extracted using a Qiagen DNeasy Tissue Extraction Kit (Qiagen, Valencia, California, USA). DNA samples were run through PCR with the digenean-specific primers Dig12 and 1500R (Invitrogen, Carlsbad, California, USA), as used in Tkach et al. (2000) and Olson et al. (2003). The PCR product was run through gel electrophoresis and purified using a Qiagen QIAquick Gel Extraction Kit, and the product was submitted to the University of Michigan DNA Sequencing Core for sequencing. Chromatograms for each sequence were examined in FinchTV version 1.4 (Geospiza, Seattle, Washington, USA; available online). ${ }^{3}$ Clean sequences were compared to those of known species using the NCBI Nucleotide BLAST algorithm (available online). ${ }^{4}$

\section{Results}

\section{Experiment 1: Combined effects of echinostomes and predators}

Compared to controls, addition of caged predators decreased survival $8 \%$, and addition of free predators decreased survival $62 \%$ (Fig. 1a). Addition of parasites decreased survival 10\% compared to controls, $42 \%$ when combined with caged predators, and 91\% when combined with free predators (Fig. 1a). In the no-predator vs. caged-predator comparison, the negative effect of caged predators on survival was significant for both dates, the negative effect of parasites on survival was significant only for the second date, and the interaction was not significant on either date (Table 1). In the nopredator vs. free-predator comparison, the negative effects of predators and parasites were significant on both dates, and the interaction was significant on both dates, suggesting a synergistic effect on survival. Finally, in the caged- vs. free-predator comparison, there was significantly lower survival of tadpoles exposed to free predators compared to those exposed to caged predators on both dates, the negative effect of parasites on survival was significant on both dates, and the interaction was significant mid-experiment, but marginally nonsignificant on the final date. The significant interaction in the caged- vs. free-predator comparison suggests that the combination of free predators and parasites had a greater interactive effect than the combination of caged predators and parasites. However, by the end of the experiment, the survival of tadpoles in the presence of free predators was reduced to such an extent that the interaction was more difficult to detect and marginally

\footnotetext{
${ }^{3}$ http://www.geospiza.com/Products/finchtv.shtml

${ }^{4}$ www.ncbi.nlm.nih.gov/BLAST/
}
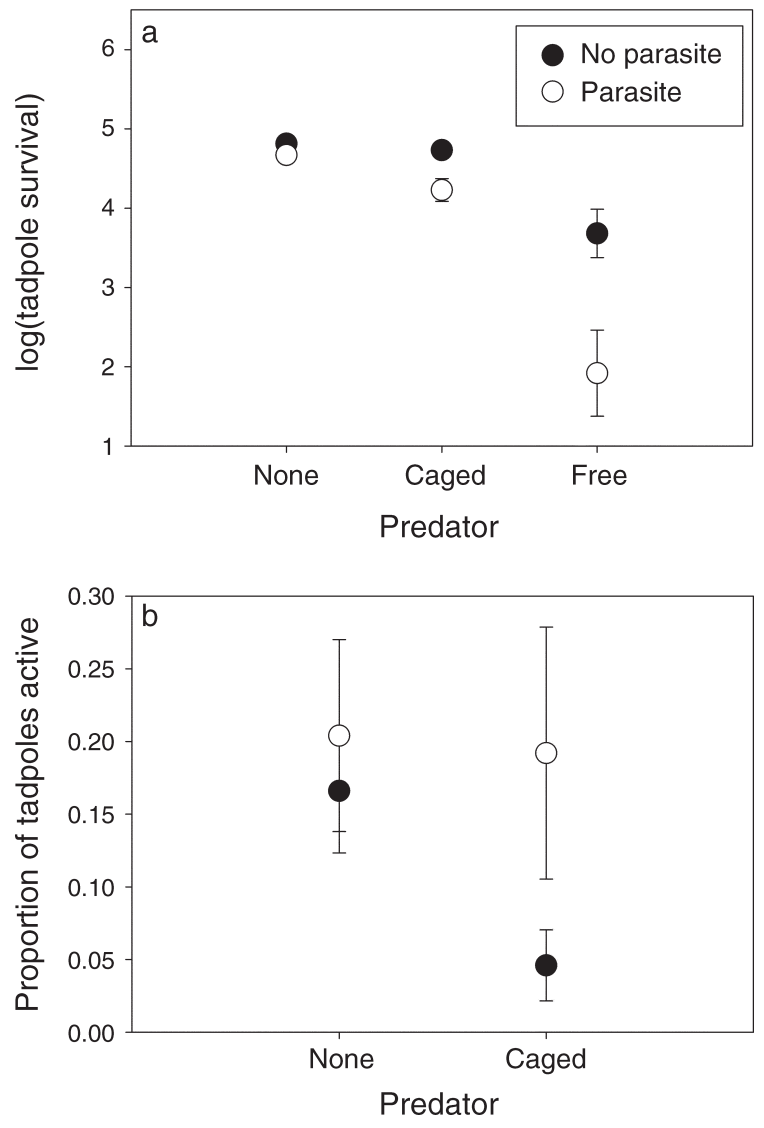

FIG. 1. Results of Experiment 1. (a) Log-transformed number of surviving green frog larvae (mean \pm SE) after 26 days in the presence of no predator, two caged (nonlethal) Anax predators, or two free (lethal) Anax, and in the absence (black circles) or presence (white circles) of echinostome parasites. (b) Proportion of visible tadpoles (mean \pm SE) that were active in the no-predator and caged-predator treatments in the presence and absence of echinostome parasites.

nonsignificant. The block effects were not significant for any comparison.

Parasites had a significant positive effect on activity levels (Fig. $1 \mathrm{~b} ; F=9.30$, df $=1,12, P=0.01$ ), predators had a marginally nonsignificant negative effect $(F=4.17$, df $=1,12, P=0.06)$, and the predator $\times$ parasite interaction was marginally nonsignificant $(F=4.50, \mathrm{df}=$ 1, 12, $P=0.06)$. The MANOVA of final mass and Gosner stage revealed no significant effect of predators (Wilks' $\Lambda=0.67, \mathrm{df}=2,20, P=0.09$ ), parasite exposure (Wilks' $\Lambda=0.65$, df $=1,20, P=0.8$ ), or the predator $\times$ parasite interaction (Wilks' $\Lambda=0.65, \mathrm{df}=2,20, P=0.8$ ). Final infection intensity did not differ among predator treatments $(F=1.51, \mathrm{DF}=2,8, P=0.3)$ or across dates $(F=1.61, \mathrm{df}=1,12, P=0.2)$, and the predator $\times$ date interaction was not significant $(F=1.691, \mathrm{df}=2,12, P=$ $0.23)$; however, the block effect was significant $(F=6.18$, $\mathrm{df}=4,8, P=0.01)$. Final infection intensity of the caged tadpoles were much lower $(1.1 \pm 0.4$ metacercariae per individual, mean $\pm \mathrm{SE})$ than for free animals $(19.4 \pm 1.7$ 
TABLE 1. Results of ANOVAs for comparisons of green frog (Rana clamitans) tadpole survival across predator and parasite treatments on day 17 and day 26 of Experiment 1.

\begin{tabular}{|c|c|c|c|}
\hline $\begin{array}{l}\text { Estimated survival period } \\
\text { and factor(s) by treatment }\end{array}$ & $F$ & $\mathrm{df}$ & $P$ \\
\hline \multicolumn{4}{|l|}{ a) Survival to day 17} \\
\hline \multicolumn{4}{|l|}{ No predator vs. caged predator } \\
\hline Predator & 7.07 & 1,12 & $0.02 *$ \\
\hline Parasite & 1.35 & 1,12 & 0.3 \\
\hline Predator $\times$ Parasite & 0.62 & 1,12 & 0.6 \\
\hline Block & 0.65 & 4,12 & 0.4 \\
\hline \multicolumn{4}{|l|}{ No predator vs. free predator } \\
\hline Predator & 63.72 & 1,12 & $<0.001^{* * *}$ \\
\hline Parasite & 12.96 & 1,12 & $0.004 * *$ \\
\hline Predator $\times$ Parasite & 10.49 & 1,12 & $0.007 * *$ \\
\hline Block & 1.84 & 4,12 & 0.2 \\
\hline \multicolumn{4}{|c|}{ Caged predator vs. free predator } \\
\hline Predator & 4.93 & 1,12 & $<0.001 * * *$ \\
\hline Parasite & 3.19 & 1,12 & $0.002 * *$ \\
\hline Predator $\times$ Parasite & 1.03 & 1,12 & $0.04 *$ \\
\hline Block & 1.42 & 4,12 & 0.2 \\
\hline \multicolumn{4}{|l|}{ b) Final survival (to day 26) } \\
\hline \multicolumn{4}{|l|}{ No predator vs. caged predator } \\
\hline Predator & 7.27 & 1,12 & $0.02 *$ \\
\hline Parasite & 11.05 & 1,12 & $0.006^{* *}$ \\
\hline Predator $\times$ Parasite & 3.457 & 1,12 & 0.09 \\
\hline Block & 0.952 & 4,12 & 0.5 \\
\hline \multicolumn{4}{|l|}{ No predator vs. free predator } \\
\hline Predator & 38.95 & 1,12 & $<0.001^{* * *}$ \\
\hline Parasite & 9.37 & 1,12 & $0.01 * *$ \\
\hline Predator $\times$ Parasite & 6.79 & 1,12 & $0.02 *$ \\
\hline Block & 1.12 & 4,12 & 0.4 \\
\hline \multicolumn{4}{|c|}{ Caged predator vs. free predator } \\
\hline Predator & 24.90 & 1,12 & $<0.001^{* * *}$ \\
\hline Parasite & 11.32 & 1,12 & $0.006 * *$ \\
\hline Predator $\times$ Parasite & 3.50 & 1,12 & 0.09 \\
\hline Block & 11.32 & 4,12 & 0.6 \\
\hline
\end{tabular}

Notes: The three predator treatments were no predator, two caged Anax predators, and two free Anax. Survival was logtransformed prior to analysis. The pairs of df values are given in sequence as between-groups $\mathrm{df}$ and within-groups $\mathrm{df}$.

metacercariae per individual) and also did not differ among predator treatments $(F=2.325$, df $=2,7, P=$ $0.2)$. Predator and parasite treatments also did not affect survival or final mass of animals in cages.

\section{Experiment 2: Effects of echinostome exposure on predation risk}

Results of the survival analysis demonstrated that the first predation event occurred more quickly in aquaria that contained infected snails $(z=2.08, P=0.04)$. Block effects were also significant $(z=-2.006, P=0.04)$. Overall predation rates on tadpoles exposed to parasites were higher than controls, with the greatest difference occurring $150 \mathrm{~min}$ after the addition of predators, at $17 \%$ lower survival in treatments with infected snails (Fig. 2). All tadpole mortality appeared to be due to predation during the experiment, because animals were either consumed or visibly damaged by predators. One infected snail was consumed by the Anax, but excluding that aquarium did not affect results.

\section{Experiment 3: Effects of echinostome infection on predation risk}

Prior exposure to echinostomes and predator cue did not affect predation rates in the mesocosm predator trials $(P>0.1)$, but predation rate decreased between week 1 and $2(F=24.85, \mathrm{df}=1,20, P<0.001)$. Mean infection intensity of tadpoles from exposure tanks was not affected by predator treatment $(F=0.012, \mathrm{df}=1,7$, $P=0.91)$ or block $(F=1.044, \mathrm{df}=7,7, P=0.48)$, and the date \pm predator treatment interaction was not significant $(F=0.882$, df $=1,14, P=0.36)$. Mean size of tadpoles from exposure tanks increased between weeks 1 and $2(F=0.58$, df $=1,28, P<0.001)$ but was not affected by predator treatment $(F=0.012, \mathrm{df}=1,21, P=$ $0.92)$, parasite treatment $(F=2.14, \mathrm{df}=1,21, P=0.16)$, the parasite $\times$ predator interaction $(F=2.06, \mathrm{df}=1,21$, $P=0.17)$, or block effects $(F=1.24, \mathrm{df}=7,21, P=0.33)$. As in the no-predator vs. caged-predator comparison in Experiment 1, survival in exposure tanks decreased in the presence of caged predators $(F=5.56, \mathrm{df}=1,21, P=$ $0.007)$ and infected snails $(F=8.85$, df $=1,21, P=$ $0.007)$, but there was no evidence for a predator $\times$ parasite interaction $(F=0.56, \mathrm{df}=1,21, P=0.46)$ or block effect $(F=1.00$, df $=7,21, P=0.46)$.

\section{Experiment 4: Density-dependent infection rates}

The initial number of animals per container and the number $\times$ container size interaction did not explain any variation in final infection intensity or survival and was excluded from the final regression models based on AIC. Log-transformed infection intensity was negatively correlated with log-transformed container size $(b=$ $-0.26, t=4.948, \mathrm{df}=20, P=0.02)$, and log-transformed container size explained a significant portion of the

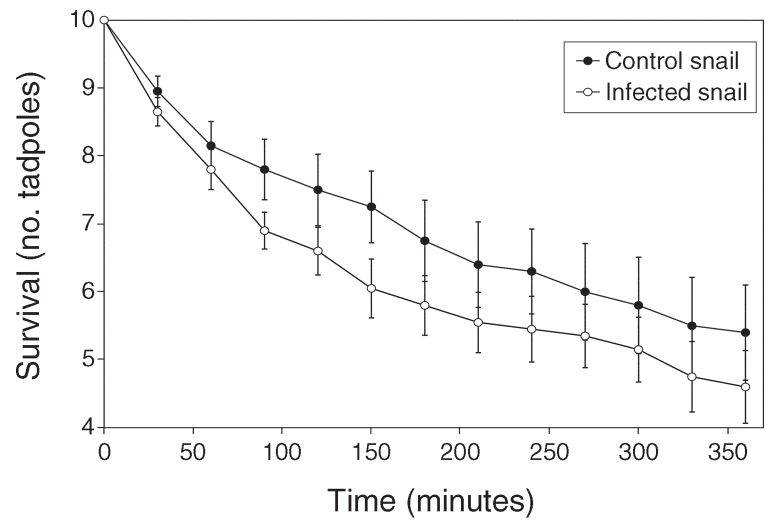

FIG. 2. Number of surviving larval green frogs (mean \pm SE) over 6-h predator trial in aquaria during Experiment 2, during which tadpoles were exposed to one Anax predator. Trials began with 10 tadpoles in each aquarium and included one uninfected control (black circles) or parasite-infected (white circles) Planorbella trivolvis snail. 
variance $\left(R^{2}=0.25, F=7.05, \mathrm{df}=1,21, P=0.02\right.$; Fig. 3). Mean survival was $62 \%$ in both control containers and containers containing infected snails. A marginally nonsignificant trend suggests that survival was lower in smaller containers $(F=4.323, \mathrm{df}=1,21, P=0.050)$. Temperatures (mean $\pm \mathrm{SE}$ ) in the $100-\mathrm{L}, 300-\mathrm{L}$, and 1300 - $\mathrm{L}$ containers were $25.2^{\circ} \pm 0.18^{\circ} \mathrm{C}, 25.2^{\circ} \pm 0.11^{\circ} \mathrm{C}$, and $25.6^{\circ} \pm 0.08^{\circ} \mathrm{C}$, and maximum daily temperatures were $27.9^{\circ} \mathrm{C}, 26.9^{\circ} \mathrm{C}$, and $26.6^{\circ} \mathrm{C}$, respectively.

\section{Experiments 5 and 6: Effects of predator cue on parasite susceptibility}

In experiment 5 , infection rates did not differ among predator treatments $(F=0.764, \mathrm{df}=1,18, P=0.4)$ and the block effect was not significant $(F=0.91, \mathrm{df}=9,18$, $P=0.5)$. Activity levels were very low $(<1 \%)$ across treatments and did not change in response to predator cue $(F=0.87, \mathrm{df}=1,47, P=0.4)$, parasite treatment $(F=$ $0.074, \mathrm{df}=1,47, P=0.79)$, the predator $\times$ parasite interaction $(F=0.14, \mathrm{df}=1,47, P=0.7)$, or block $(F=$ $1.86, \mathrm{df}=9,47, P=0.08)$.

In experiment 6 , survival decreased with parasite exposure level $(z=-2.241, P=0.02)$, but there was no effect of predator cue $(z=-0.214, P=0.8)$ or evidence of an interaction $(z=0.619, P=0.5)$. Final mass was not affected by parasite exposure $(t=1.01, P=0.3)$ or predator cue level $(t=-0.40, P=0.7)$. Activity decreased at higher levels of predator cue $(t=-2.82, P$ $=0.008$ ), but was not affected by parasite exposure level $(t=1.635, P=0.1)$.

\section{Parasite identification}

Echinostomes dissected from snails from four ponds (Kaiser South, Duck Pond, West Marsh Dam Pond, and East Marsh) were identified as Echinostoma revolutum based on comparison of our sequence in NCBI Nucleotide BLAST (99\% similarity, accession AY222246). Echinostomes from the snail from West Marsh \#11 were identified as Echinoparyphium rubrum (100\% similarity, accession JF820595). All experiments except Experiment 2 used snails only where $E$. revolutum was found. Snails used in Experiment 2 were from all five ponds, including eight snails from West Marsh \#11; consequently, a mixture of snails infected with either $E$. revolutum or E. rubrum was used in Experiment 2. Because parasites were not identified from all snails used, a mixture of echinostome species may have been used in other experiments if E. rubrum and E. revolutum co-occurred in some ponds.

\section{Discussion}

Our results demonstrate that the joint presence of predators and parasites had strong nonadditive effects on survival of anuran larvae. As expected, both parasites and free predators decreased larval green frog survival, but together their synergistic effect amplified this mortality by $21 \%$. Importantly, we conducted a series of follow-up experiments to isolate the mechanistic basis

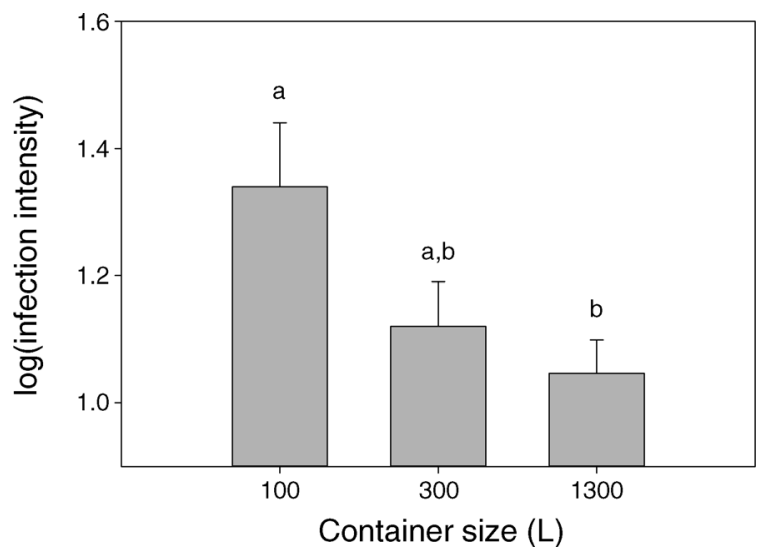

FIG. 3. Log-transformed individual infection intensity (number of metacercariae, mean $+\mathrm{SE}$ ) of tadpoles in 100-L, $300-\mathrm{L}$, and $1300-\mathrm{L}$ containers in Experiment 4. Different lowercase letters indicate significant differences between sizes (Tukey HSD, $\alpha=0.05$ ). The number of tadpoles per container ranged from 25 to 250 , but the number of tadpoles did not affect infection intensities $(F=0.12, \mathrm{df}=1,20, P=0.7)$.

of this interaction. Our results directly support our second hypothesis that free predators and parasites have synergistic effects, which implies that the combined effects of predators and parasites may have complex consequences for amphibian demographic processes, because infection intensities here fall well within the range observed in the field (Skelly et al. 2006; J. A. Marino and M. P. Holland, unpublished data).

Our results suggest that the effect of parasiteavoidance behavior on predation risk (Mechanism A) contributes to the observed interaction. The observed increase in activity in the presence of infected snails in Experiment 1, even when predator cues were present, suggests that tadpoles increased activity to avoid cercariae, which in turn likely increased susceptibility to predators. The results of Experiment 2 demonstrate that predation rate increased in the presence of parasites, reinforcing this interpretation. This mechanism therefore is driven by a fundamental difference in the behavioral response of larval frogs to parasites as opposed to predators. Increased activity (i.e., avoidance behavior) of larval frogs in response to cercariae enhances the ability of larval frogs to avoid infection by trematode cercariae (Koprivnikar et al. 2006, Rohr et al. 2009, Daly and Johnson 2011). However, increased activity also can increase larval frog susceptibility to visual predators (Anholt and Werner 1998). This tradeoff between susceptibility to parasites and predators is the most likely explanation for the observed interaction demonstrated here. Such a trade-off probably also contributes to the interactive effects of predatory salamanders and trematode parasites on larval wood frogs (Belden and Wojdak 2011) and the positive effects of fish predators on infection (Thiemann and Wassersug 2000, Szuroczki and Richardson 2012). 
The observed interaction here may result from constraints on the ability of tadpoles to reliably assess risks from the combination of natural enemies. The engagement of tadpoles in parasite avoidance behavior despite the presence of predator cue is surprising, because the individual fitness cost of a predation event outweighs any sublethal costs of parasitism. Here, tadpoles may have perceived greater risk through tactile cues of cercariae than from predator cue. This response may not necessarily be maladaptive, if the immediate benefits of an avoidance response (i.e., escape from cercariae) outweigh the risk of increased visibility in a natural setting, especially for smaller tadpoles, which may be generally less visible and experience greater susceptibility to parasites (Holland et al. 2007). Alternatively, tadpoles may be engaging in a generalized reflexive response (i.e., a physiological response) to irritation, which is maladaptive in the presence of predators. Future research varying the force of infection and perceived threats from predators could provide more insight into the limitations on tadpoles' responses to each threat.

A predation risk-parasite susceptibility trade-off probably occurs in other systems as well (e.g., Rutherford et al. 2007), because many traits play an important role in susceptibility to parasitism (reviewed in Hart 1990, Moore 2002) as well as predation (e.g., Biro et al. 2003, Strobbe et al. 2011), and these two threats can pose conflicting pressures when the optimal response to predation risk differs from that to parasitism. From an ecological perspective, the consequences of this trade-off may be elevated parasite transmission or higher predation rates, depending on the perceived fitness costs associated with each natural enemy. Such effects may synergistically alter disease prevalence and population dynamics. From an evolutionary perspective, this tradeoff could create an external constraint on the evolution of phenotypic plasticity in response to natural enemies (i.e., induced defenses), leading to traits that may appear to be maladaptive in the context of a single species-pair interaction.

Our results also suggest that alternative mechanisms (B-D), although likely important in other contexts or systems, made small or no contribution to the observed interaction here. We expected that infected individuals would experience morbidity and thus would be less able to escape from predators (Mechanism B). The results of Experiment 3, however, suggest that parasite infection did not influence predation susceptibility. It is possible that an effect of infection on escape ability, if present, may have been countered by lowered overall activity of more infected individuals after infection (observed in Thiemann and Wassersug 2000) and thus reduced visibility to predators.

If per capita infection rates increase at lower densities, and parasite-induced mortality increases nonlinearly with infection rates (i.e., mortality occurs only at high infection intensities), predator-induced reduction in prey density could magnify effects of parasites on survival (Mechanism C). However, the lack of an effect of lethal predators on final infection intensity in Experiment 1 and the results of Experiment 4 suggest that predators did not drive higher per capita infection rates through effects on tadpole density. A 10-fold increase in density in Experiment 4 at the scale of Experiment 1 (i.e., 1300L cattle tank), did not influence final infection intensity, suggesting that infection rates are not limited by the number of tadpole hosts at this scale. Interestingly, the significant effect of container size on final infection intensity suggests that infection rates can depend on the scale of host-parasite interaction, which will be important to extrapolate effects measured in the laboratory to larger scales. An explanation for this result is that the change in spatial scale increases the contact rate between parasites and hosts and, thus, infection rates. Temperature also varied across container sizes, but the relatively small mean difference $\left(<0.5^{\circ} \mathrm{C}\right)$ is not likely to entirely explain the observed pattern.

Notably, caged predators had a significant effect on survival in mesocosms (Experiments 1 and 3), a nonconsumptive effect that has been previously reported in this system (Werner and Anholt [1996]; for a case with odonate larvae, see also McCauley et al. [2011]). However, contrary to our first hypothesis, the combination of caged predators with echinostomes had additive, rather than synergistic, effects on survival. This finding was consistent with the findings of Raffel et al. (2010), who found that the effects of Echinostoma trivolvis and caged newt predators (Notophthalmus viridescens) on larval American toads (Bufo americanus) were additive. The results of Experiment 1 were insufficient to rule out the contributions of predator cue to the observed interaction entirely (i.e., Mechanism D), because predator cues generated by free predators can exceed those of caged predators (Peacor and Werner 2001). However, the results of Experiments 5 and 6 provide further support that higher cue concentrations did not explain the observed interaction in Experiment 1 , because predator cue did not influence infection rates or post-exposure effects of parasites on hosts.

These results contrast with the findings of others, potentially due to differences in design (e.g., predator species, experiment duration, spatial scale, and parasite exposure level). The lack of an effect of parasites or predator cues on activity levels in Experiment 5 was surprising, given demonstrations of such effects elsewhere (e.g., Relyea 2001a, Rohr et al. 2009). Additionally, we failed to observe the positive effect of predator cue on individual infection intensity documented elsewhere (Thiemann and Wassersug 2000, Szuroczki and Richardson 2012). A possible explanation is that we used a relatively small size class $(\sim 23 \mathrm{mg})$, which exhibited a low baseline activity level, so behavioral effects of natural enemies may have been difficult to observe. For our investigation, however, effects on smaller size classes are more relevant, as effects of 
infection on survival decline in larger tadpoles (Holland et al. 2007). Finally, although we did not observe interactive effects of echinostomes and predator cue on survival in Experiment 6, Koprivnikar (2010) reported an interactive effect of caged predators and echinostome infection on larval leopard frog (Rana pipiens) survival. However, this interaction may have resulted partly from an unexplained positive effect of echinostomes on leopard frog survival in the absence of predators. Additionally, differences among species in parasite susceptibility (e.g., Johnson et al. 2012) may explain why the same interaction did not occur here.

One final mechanism that we did not address here may be important in other systems. Nonlinearities in predator-prey interactions (e.g., Type II functional response; Holling 1959) could also drive nonadditive effects and can be altered by parasites (Dick et al. 2010). However, given the relatively small effect of echinostomes on survival in the absence of predators in Experiment 1, this mechanism did not likely contribute to the observed interaction.

Given the ubiquity of parasitism as a lifestyle (Dobson et al. 2008) and the dominance of food web links by parasites (Lafferty et al. 2008), measuring the overall effects of parasites will be essential to developing predictive models of trophic interactions within many animal communities. Synergistic effects of predators and parasites provide additional challenges to the already difficult task of measuring interaction strengths. However, our approach of separately evaluating potential mechanisms provides a powerful method to determine which processes are dominant or unimportant. In particular, trait-mediated trade-offs in susceptibility are likely drivers of potential synergisms and merit greater attention. Such trade-offs may be mediated by behavior (as evidenced here), by physiology (Ramirez and Snyder 2009), or by other traits (e.g., growth, Duffy et al. 2011). The resulting synergism could modify important ecological processes, such as dilution effects, trophic cascades, and keystone effects.

In addition to furthering our knowledge of the role of multiple natural enemies in animal communities, these results have important implications for amphibian conservation and wetland management, as echinostomes have been reported to be in higher abundance near human activities, such as pesticide use (Rohr et al. 2008) and urbanization (Skelly et al. 2006). A realistic evaluation of the impacts of higher parasite abundance must include the influence of existing stressors of amphibians, which typically include predators. More generally, these results can inform our understanding of interactions among multiple stressors on amphibian populations, which is of particular importance due to recent global amphibian declines (Stuart et al. 2004).

\section{ACKNOWLEDGMENTS}

We thank Ariel Heldt and Jared Vitala for assistance in conducting the experiments; Marissa Baranowski for assistance with dissections; members of the Werner lab for helpful discussion; and Liliana Cortés Ortiz and Tom Duda for assistance with molecular work in the University of Michigan Genomic Diversity Laboratory. The comments of Manja Holland, Catherine Searle, Dylan Grippi, and two anonymous reviewers greatly improved this manuscript. This work was supported by NSF DEB 1110137 and the University of Michigan Edwin S. George Reserve Scholarship Award.

\section{Literature Cited}

Altmann, J. 1974. Observational studies of behavior: sampling methods. Behaviour 49:227-267.

Anholt, B. R., and E. E. Werner. 1998. Predictable changes in predation mortality as a consequence of changes in food availability and predation risk. Evolutionary Ecology 12: 729-738.

Behringer, D. C., and M. J. Butler. 2010. Disease avoidance influences shelter use and predation in Caribbean spiny lobster. Behavioral Ecology and Sociobiology 64:747-755.

Belden, L. K., and J. M. Wojdak. 2011. The combined influence of trematode parasites and predatory salamanders on wood frog (Rana sylvatica) tadpoles. Oecologia 166:1077-1086.

Biro, P. A., J. R. Post, and E. A. Parkinson. 2003. From individuals to populations: Prey fish risk-taking mediates mortality in whole-system experiments. Ecology 84:24192431.

Bolker, B., M. Holyoak, V. Krivan, L. Rowe, and O. Schmitz. 2003. Connecting theoretical and empirical studies of traitmediated interactions. Ecology 84:1101-1114.

Bourdeau, P. E., and F. Johansson. 2012. Predator-induced morphological defences as by-products of prey behaviour: a review and prospectus. Oikos 121:1175-1190.

Daly, E. W., and P. T. J. Johnson. 2011. Beyond immunity: quantifying the effects of host anti-parasite behavior on parasite transmission. Oecologia 165:1043-1050.

Diaz, M., and C. L. Alonso. 2003. Wood mouse (Apodemus sylvaticus) winter food supply: density, condition, breeding, and parasites. Ecology 84:2680-2691.

Dick, J. T. A., M. Armstrong, H. C. Clarke, K. D. Farnsworth, M. J. Hatcher, M. Ennis, A. Kelly, and A. M. Dunn. 2010. Parasitism may enhance rather than reduce the predatory impact of an invader. Biology Letters 6:636-638.

Dobson, A., K. D. Lafferty, A. M. Kuris, R. F. Hechinger, and W. Jetz. 2008. Homage to Linnaeus: How many parasites? How many hosts? Proceedings of the National Academy of Sciences USA 105:11482-11489.

Duffy, M. A., J. M. Housley, R. M. Penczykowski, C. E. Caceres, and S. R. Hall. 2011. Unhealthy herds: indirect effects of predators enhance two drivers of disease spread. Functional Ecology 25:945-953.

Dwyer, G., J. Dushoff, and S. H. Yee. 2004. The combined effects of pathogens and predators on insect outbreaks. Nature 430:341-345.

Fenton, A., and S. A. Rands. 2006. The impact of parasite manipulation and predator foraging behavior on predatorprey communities. Ecology 87:2832-2841.

Fried, B., P. L. Pane, and A. Reddy. 1997. Experimental infection of Rana pipiens tadpoles with Echinostoma trivolvis cercariae. Parasitology Research 83:666-669.

Gosner, K. L. 1960. A simplified table for staging anuran embryos and larvae with notes on identification. Herpetologica 16:183-190.

Hart, B. L. 1990. Behavioral adaptations to pathogens and parasites: Five strategies. Neuroscience and Biobehavioral Reviews 14:273-294.

Hatcher, M. J., J. T. A. Dick, and A. M. Dunn. 2006. How parasites affect interactions between competitors and predators. Ecology Letters 9:1253-1271.

Holland, M. P., D. K. Skelly, M. Kashgarian, S. R. Bolden, L. M. Harrison, and M. Cappello. 2007. Echinostome infection in green frogs (Rana clamitans) is stage and age dependent. Journal of Zoology 271:455-462. 
Holling, C. S. 1959. Some characteristics of simple types of predation and parasitism. Canadian Entomologist 91:385398.

Horak, P., L. Tummeleht, and H. Talvik. 2006. Predator threat, copulation effort and immunity in male rats (Rattus norvegicus). Journal of Zoology 268:9-16.

Hudson, P. J., A. P. Dobson, and D. Newborn. 1992. Do parasites make prey vulnerable to predation? Red grouse and parasites. Journal of Animal Ecology 61:681-692.

Ives, A. R., and D. L. Murray. 1997. Can sublethal parasitism destabilize predator-prey population dynamics? A model of snowshoe hares, predators and parasites. Journal of Animal Ecology 66:265-278.

Johnson, P. T. J., E. R. Preu, D. R. Sutherland, J. M. Romansic, B. Han, and A. R. Blaustein. 2006. Adding infection to injury: Synergistic effects of predation and parasitism on amphibian malformations. Ecology 87:22272235.

Johnson, P. T. J., J. R. Rohr, J. T. Hoverman, E. Kellermanns, J. Bowerman, and K. B. Lunde. 2012. Living fast and dying of infection: host life history drives interspecific variation in infection and disease risk. Ecology Letters 15:235-242.

Kagan, I. G. 1951. Aspects in the life history of Neoleucochloridium problematicum (Magath, 1920) New Comb. and Leucochloridium cyanocittae McIntosh, 1932 (Trematoda: Brachylaemidae). Transactions of the American Microscopical Society 70:281.

Kanev, V. R., M. Sterner, and B. Fried. 2000. An overview of the biology of echinostomes. Pages 1-29 in B. Fried and T. K. Graczyk, editors. Echinostomes as experimental models for biological research. Kluwer Academic Publishers, Boston, Massachusetts, USA.

Koprivnikar, J. 2010. Interactions of environmental stressors impact survival and development of parasitized larval amphibians. Ecological Applications 20:2263-2272.

Koprivnikar, J., M. R. Forbes, and R. L. Baker. 2006. On the efficacy of anti-parasite behaviour: a case study of tadpole susceptibility to cercariae of Echinostoma trivolvis. Canadian Journal of Zoology 84:1623-1629.

Lafferty, K. D. 1999. The evolution of trophic transmission. Parasitology Today 15:111-115.

Lafferty, K. D., et al. 2008. Parasites in food webs: The ultimate missing links. Ecology Letters 11:533-546.

Lafferty, K. D., and A. K. Morris. 1996. Altered behavior of parasitized killifish increases susceptibility to predation by bird final hosts. Ecology 77:1390-1397.

Lagrue, C., N. Kaldonski, M. J. Perrot-Minnot, B. Motreuil, and L. Bollache. 2007. Modification of hosts' behavior by a parasite: field evidence for adaptive manipulation. Ecology 88:2839-2847.

Lefevre, T., C. Lebarbenchon, M. Gauthier-Clerc, D. Misse, R. Poulin, and F. Thomas. 2009. The ecological significance of manipulative parasites. Trends in Ecology and Evolution 24: 41-48.

Luong, L. T., B. A. Vigliotti, and P. J. Hudson. 2011. Strong density-dependent competition and acquired immunity constrain parasite establishment: Implications for parasite aggregation. International Journal for Parasitology 41:505511.

McCauley, S. J., L. Rowe, and M. J. Fortin. 2011. The deadly effects of "nonlethal" predators. Ecology 92:2043-2048.

Moore, J. 2002. Parasites and the behavior of animals. Oxford University Press, New York, New York, USA.

Morley, N. J., M. E. Adam, and J. W. Lewis. 2010. The effects of host size and temperature on the emergence of Echinoparyphium recurvatum cercariae from Lymnaea peregra under natural light conditions. Journal of Helminthology 84:317326.

Najarian, H. H. 1954. Developmental stages in the life cycle of Echinoparyphium flexum (Linton, 1892) Dietz, 1910 (Trematoda: Echinostomatidae). Journal of Morphology 94:165.
Olson, P. D., T. H. Cribb, V. V. Tkach, R. A. Bray, and D. T. J. Littlewood. 2003. Phylogeny and classification of the Digenea (Platyhelminthes: Trematoda). International Journal for Parasitology 33:733-755.

Palacios, M. J., F. Valera, and A. Barbosa. 2012. Experimental assessment of the effects of gastrointestinal parasites on offspring quality in chinstrap penguins (Pygoscelis antarctica). Parasitology 139:819-824.

Peacor, S. D., and E. E. Werner. 2001. The contribution of trait-mediated indirect effects to the net effects of a predator. Proceedings of the National Academy of Sciences USA 98: 3904-3908.

Peacor, S. D., and E. E. Werner. 2004. How dependent are species-pair interaction strengths on other species in the food web? Ecology 85:2754-2763.

Poulin, R. 1994. Meta-analysis of parasite-induced behavioural changes. Animal Behaviour 48:137-146.

Poulin, R. 1995. "Adaptive" changes in the behaviour of parasitized animals: a critical review. International Journal for Parasitology 25:1371-1383.

R Development Core Team. 2012. R version 2.15. R: A language and environment for statistical computing. R Foundation for Statistical Computing, Vienna, Austria. http://www.R-project.org/

Raffel, T. R., J. T. Hoverman, N. T. Halstead, P. J. Michel, and J. R. Rohr. 2010. Parasitism in a community context: traitmediated interactions with competition and predation. Ecology 91:1900-1907.

Ramirez, R. A., and W. E. Snyder. 2009. Scared sick? Predatorpathogen facilitation enhances exploitation of a shared resource. Ecology 90:2832-2839.

Relyea, R. A. 2001a. Morphological and behavioral plasticity of larval anurans in response to different predators. Ecology 82:523-540.

Relyea, R. A. 2001b. The relationship between predation risk and antipredator responses in larval anurans. Ecology 82: $541-554$

Relyea, R. A. 2004. Fine-tuned phenotypes: tadpole plasticity under 16 combinations of predators and competitors. Ecology 85:172-179.

Rohr, J. R., et al. 2008. Agrochemicals increase trematode infections in a declining amphibian species. Nature 455:12351239.

Rohr, J. R., A. Swan, T. R. Raffel, and P. J. Hudson. 2009. Parasites, info-disruption, and the ecology of fear. Oecologia 159:447-454.

Rutherford, P. L., R. L. Baker, and M. R. Forbes. 2007. Do larval damselflies make adaptive choices when exposed to both parasites and predators? Ethology 113:1073-1080.

Schell, S. C. 1985. Handbook of trematodes of North America north of Mexico. University Press of Idaho, Moscow, Idaho, USA.

Skelly, D. K., S. R. Bolden, M. P. Holland, L. K. Freidenburg, N. A. Friedenfelds, and T. R. Malcolm. 2006. Urbanization and disease in amphibians. Pages 153-167 in S. K. Collinge and C. Ray, editors. Disease ecology: Community structure and pathogen dynamics. Oxford University Press, Cary, North Carolina, USA.

Strobbe, F., M. A. McPeek, M. De Block, and R. Stoks. 2011. Fish predation selects for reduced foraging activity. Behavioral Ecology and Sociobiology 65:241-247.

Stuart, S. N., J. S. Chanson, N. A. Cox, B. E. Young, A. S. L. Rodrigues, D. L. Fischman, and R. W. Waller. 2004. Status and trends of amphibian declines and extinctions worldwide. Science 306:1783-1786.

Szuroczki, D., and J. M. L. Richardson. 2012. The behavioral response of larval amphibians (Ranidae) to threats from predators and parasites. PLoS One 7(11):e49592.

Thiemann, G. W., and R. J. Wassersug. 2000. Patterns and consequences of behavioural responses to predators and 
parasites in Rana tadpoles. Biological Journal of the Linnean Society 71:513.

Thomas, F., F. Renaud, T. de Meeus, and R. Poulin. 1998. Manipulation of host behaviour by parasites: ecosystem engineering in the intertidal zone? Proceedings of the Royal Society B 265:1091-1096.

Tkach, V., J. Pawlowski, and J. Mariaux. 2000. Phylogenetic analysis of the suborder Plagiorchiata (Platyhelminthes, Digenea) based on partial lsrDNA sequences. International Journal for Parasitology 30:83-93.

Van Buskirk, J., and S. A. McCollum. 2000. Functional mechanisms of an inducible defence in tadpoles: morphology and behaviour influence mortality risk from predation. Journal of Evolutionary Biology 13:336-347.
Vonesh, J. R., and C. W. Osenberg. 2003. Multi-predator effects across life-history stages: non-additivity of egg- and larval-stage predation in an African treefrog. Ecology Letters 6:503-508.

Werner, E. E., and B. R. Anholt. 1996. Predator-induced behavioral indirect effects: Consequences to competitive interactions in anuran larvae. Ecology 77:157-169.

Werner, E. E., and S. D. Peacor. 2003. A review of traitmediated indirect interactions in ecological communities. Ecology 84:1083-1100.

Wootton, J. T. 1994. The nature and consequences of indirect effects in ecological communities. Annual Review of Ecology and Systematics 25:443-466. 